\title{
Microbiome Structure of the Aphid Myzus persicae (Sulzer) Is Shaped by Different Solanaceae Plant Diets
}

\author{
Baoyu He ${ }^{1}$, Xiaoyulong Chen ${ }^{1,2}$, Hong Yang ${ }^{1,2 *}$ and Tomislav Cernava ${ }^{2,3 *}$ \\ ${ }^{1}$ Guizhou Provincial Key Laboratory for Agricultural Pest Management of the Mountainous Region, Guizhou University, \\ Guiyang, China, ${ }^{2}$ College of Tobacco Science, Guizhou University, Guiyang, China, ${ }^{3}$ Institute of Environmental \\ Biotechnology, Graz University of Technology, Graz, Austria
}

OPEN ACCESS

Edited by:

George Tsiamis,

University of Patras, Greece

Reviewed by:

Adriana Alvarez,

Universidad Nacional de Salta,

Argentina

Ana Elena Pérez-Cobas,

Ramón y Cajal Institute for Health

Research, Spain

*Correspondence:

Tomislav Cernava

tomislav.cernava@tugraz.at

Hong Yang

axyridis@163.com

Specialty section:

This article was submitted to

Systems Microbiology,

a section of the journal

Frontiers in Microbiology

Received: 12 February 2021

Accepted: 07 June 2021

Published: 05 July 2021

Citation:

He $B$, Chen $X$, Yang $H$ and

Cernava T (2021) Microbiome

Structure of the Aphid Myzus persicae

(Sulzer) Is Shaped by Different

Solanaceae Plant Diets.

Front. Microbiol. 12:667257.

doi: 10.3389/fmicb.2021.667257
Myzus persicae (Sulzer) is an important insect pest in agriculture that has a very broad host range. Previous research has shown that the microbiota of insects has implications for their growth, development, and environmental adaptation. So far, there is little detailed knowledge about the factors that influence and shape the microbiota of aphids. In the present study, we aimed to investigate diet-induced changes in the microbiome of $M$. persicae using high-throughput sequencing of bacterial 16S ribosomal RNA gene fragments in combination with molecular and microbiological experiments. The transfer of aphids to different plants from the Solanaceae family resulted in a substantial decrease in the abundance of the primary symbiont Buchnera. In parallel, a substantial increase in the abundance of Pseudomonas was observed; it accounted for up to $69.4 \%$ of the bacterial community in $M$. persicae guts and the attached bacteriocytes. In addition, we observed negative effects on aphid population dynamics when they were transferred to pepper plants (Capsicum annuum L.). The microbiome of this treatment group showed a significantly lower increase in the abundance of Pseudomonas when compared with the other Solanaceae plant diets, which might be related to the adaptability of the host to this diet. Molecular quantifications of bacterial genera that were substantially affected by the different diets were implemented as an additional verification of the microbiome-based observations. Complementary experiments with bacteria isolated from aphids that were fed with different plants indicated that nicotine-tolerant strains occur in Solanaceae-fed specimens, but they were not restricted to them. Overall, our mechanistic approach conducted under controlled conditions provided strong indications that the aphid microbiome shows responses to different plant diets. This knowledge could be used in the future to develop environmentally friendly methods for the control of insect pests in agriculture.

Keywords: insect microbiome, Solanaceae, Nicotiana tabacum, Solanum melongena, Capsicum annuum

\section{INTRODUCTION}

Microorganisms are ubiquitous in the environment and often associated with eukaryotic hosts. During the last decades, it has been shown that microorganisms in plants and animals often fulfill important functions (Van der Ent et al., 2009; Fuchs, 2010). Individual plants and animals often harbor more than 1,000 different microbial species; some of them are crucial determinants for 
their host's health and productivity because they can modulate metabolism, improve pathogen defense, and increase resource uptake (Van Der Heijden et al., 2008; Etalo et al., 2018; Alavi et al., 2020; Matsumoto et al., 2021). Insects, analogous to other animals, also have a close relationship with their microbiota; it was previously shown to have a substantial impact on insect ecology and various implications for evolutionary host development (Lewis and Lizé, 2015). Targeted studies have provided evidence that the composition of the insect microbiome is shaped by both geographic location and diet (Guo et al., 2019; Xu et al., 2019; Ma et al., 2021). Symbionts are found ubiquitously in insects among a variety of other microbes with as yet unknown functions. They can play various beneficial roles, such as promotion of growth and defense against natural enemies (Lee et al., 2017; Oliver and Perlman, 2020). Moreover, they support the adaptability of insects to adverse environmental conditions (Dunbar et al., 2007).

Aphids are sap-sucking insects that belong to the globally widespread insect order Hemiptera. Over 4,000 different aphid species were described within this order so far (Dixon et al., 1987). Therein, over 250 species are considered to be among the most destructive pests of cultivated plants (Blackman and Eastop, 1984). Aphids can negatively affect their host plants in different ways. They can damage plants via direct and indirect mechanisms; the latter is especially due to transmitted viruses. It is currently assumed that aphids can vector more than 200 viral diseases, which accounts for over $30 \%$ of all relevant plant viruses (Brault et al., 2010). In addition, aphids often served in the past as models to study microorganism-insect interactions (Oliver et al., 2010). The bacterial genus Buchnera, which includes various symbiont species that can be obligate for their hosts, was found to supply vitamins and essential amino acids that are not taken up through their plant diets, such as methionine and tryptophan (Birkle et al., 2002; Akman Gündüz and Douglas, 2009). In return, the aphid can also provide distinct compounds to its symbionts, which they cannot synthesize due to evolutionary losses of distinct biosynthetic genes (Brinza et al., 2009). Their interaction is therefore obligate and mutualistic in a way that neither partner can reproduce in the absence of the other. Buchnera cells are commonly distributed in the cytosol of specialized host cells around the aphid gut; they are often subjected to changes during their host's lifecycle (Simonet et al., 2016). In some insects, Buchnera was shown to be enriched before adulthood and to gradually decrease in adult insects (Simonet et al., 2018). In addition to the obligatory Buchnera symbionts, a broad range of secondary symbionts was previously discovered in aphids. Some of them are known to manipulate host reproduction, whereas others are involved in a mutualistic interplay that can increase host survival or fecundity, such as Serratia symbiotica, Hamiltonella defensa, Regiella inseticola, Rickettsia, Rickettsiella, Spiroplasma, Wolbachia, Arsenophonus, and Fukatsuia symbiotica (Scarborough et al., 2005; Russell and Moran, 2006; De Clerck et al., 2015; Ayoubi et al., 2020). Among aphid species, Myzus persicae (Sulzer) is one of the most destructive, cosmopolitan, and generalist agricultural pests. It can cause substantial damage to more than 400 plant species (Quaglia et al., 1993). Some subspecies are specifically adapted to Solanaceae plants, which are economically the third most important plant family, consisting of approximately 2,700 plant species (Olmstead and Bohs, 2006; Tapia et al., 2008). Especially the cultivation of pepper (Capsicum annuum L.), eggplant (Solanum melongena L.), and tobacco (Nicotiana tabacum L.) is often affected by $M$. persicae, which can substantially reduce the amount and quality of harvested plant products. Nowadays, the control of $M$. persicae is mainly based on chemical control; however, insecticides have brought serious resistance problems as a result of their extensive use. We aimed at further expanding the knowledge related to factors that shape the aphid microbiome by conducting feeding experiments under controlled conditions. We assume that this knowledge could provide an extended basis for the development of a new control strategy for $M$. persicae. Previous studies with a similar aim found potential implications of the sampling location and host plant; however, the shaping capacity of the latter on the aphid's microbiota remained to be explored in more detail (Xu et al., 2019). This especially applies to host changes with highly different secondary metabolite profiles. In the present study, we hypothesized that the microbiome of aphids undergoes significant changes as they move from an initial host that produces low levels of bioactive compounds to different plants within the Solanaceae family. We selected three plant species that were fed separately to $M$. persicae populations in a controlled environment. After rearing them on cabbage (Brassica rapa L. var. pekinensis), they were transferred to eggplant, pepper, and tobacco plants. After 2 weeks, we dissected the aphid guts to which bacteriocytes are attached and extracted the total community DNA. Following a targeted amplification of bacterial 16S ribosomal RNA (rRNA) gene fragments and high-throughput sequencing, the data were subjected to an explanatory bioinformatics approach. From a long-term point of view, our findings may facilitate the development of microbiome management approaches targeting symbiotic bacteria of aphids to minimize their destructive impact on crops.

\section{MATERIALS AND METHODS}

\section{Myzus persicae Rearing and Sample Preparation}

Plants used to feed aphids were cultivated from seeds to provide controlled conditions, especially in terms of agrochemical residues that might affect the microbiota. Cabbage seeds (B. rapa L. var. pekinensis) were obtained from Guizhou Debang Agricultural Products Co., Ltd. (Guiyang, Guizhou; location: $\mathrm{N} 26^{\circ} 57^{\prime} 83.42^{\prime \prime}, \mathrm{E} 106^{\circ} 71^{\prime} 34.78^{\prime \prime}$ ), eggplant seeds (S. melongena L. cv. Zilong No. 8) and pepper seeds (C. annuum cv. Gui Yan No. 13) from Guizhou Lifeng Zhongye Co., Ltd. (Guiyang, Guizhou, China), and tobacco seeds of the cultivar MS K326 from Yuxi Zhong Yan Seed Co., Ltd. (Yuxi, Yunnan; location: $\mathrm{N} 24^{\circ} 19^{\prime} 54.32^{\prime \prime}$, E102 $\left.31^{\prime} 44.95^{\prime \prime}\right)$. For their cultivation, soil, perlite, and vermiculite were mixed in a 3:3:1 ratio and irrigated with water after the respective seeds were added. They were kept in an incubator at $25^{\circ} \mathrm{C}, 66 \%$ relative humidity, and $16-\mathrm{h} / 8$ $\mathrm{h}$ day/night cycles for around 10 days until the seeds started to germinate. At the seedling stage, they were transferred to 
larger pots $(11.5 \times 9.5 \mathrm{~cm})$ with the same soil mixture as mentioned earlier. The pots were then placed into mesh cages $(35 \times 35 \times 28 \mathrm{~cm})$. One plant was placed into each mesh cage with 12 replicates for each Solanaceae plant diet. For the control group, aphids were kept for the same duration on a cabbage diet in 12 additional mesh cages. When the plants reached stable growth, adult $M$. persicae aphids reared on cabbage were transferred together with cabbage leaves cut from the plants into the mesh cages with the Solanaceae plants to allow a natural transition; the cabbage leaves were subsequently removed from the containers. A complementary experiment with the same setup and six replicates per plant species was conducted to assess the population dynamics of $M$. persicae on the plant diets that were implemented. Observations and counts were made on the first day of transfer from cabbage to Solanaceae plants and continued for 14 days. The average number of aphids was obtained every day and used to construct a graph showing the population dynamics. The temperature and humidity were monitored with an EL-USB-2 device (Lascar Electronics). During the whole feeding experiment, the temperature ranged between 18.5 and $33^{\circ} \mathrm{C}$, while the relative humidity ranged between 47 and 98\% (Supplementary Figure 1). After 2 weeks on the respective diets, the adult aphids were removed for dissections. For surface sterilization, $M$. persicae was submerged in $75 \%$ ethanol for $10 \mathrm{~s}$; the step was repeated in a different tube and followed by transfer into sterile water to remove the residual ethanol. Then, the aphids were placed into a phosphate-buffered saline buffer to prepare them for dissection. Disposable sterile syringe needles (0.3 $\times 13$ mm; Zhejiang Kangdelai Medical Equipment Co., Ltd.) and tweezers (ST-11; Shenzhen Deer Fairy Technology Co., Ltd.) were used to remove the guts, to which also bacteriocytes are attached, under a stereoscope (Olympus SZ2-ILST). In the first step, the heads of the adult aphids were clamped with tweezers. Then, using sterile disposable syringe needles, the abdomens of the aphids were cut open. For each sample, 50 guts from aphids kept in the same mesh cage were collected in a sterile $1.5-\mathrm{ml}$ tube. This was replicated 12 times for each plant diet that was administered in a separate mesh cage. All samples were stored on ice during the dissection process. In total, 48 composite samples, each consisting of 50 aphid guts from separate mesh cages, were obtained and stored at $-80^{\circ} \mathrm{C}$ before total community DNA extraction. The whole experiment procedure is shown schematically in Supplementary Figure 2.

\section{Total Community DNA Extractions From Aphid Guts}

All gut samples were processed with a DNA extraction kit (Fast DNA SPIN Kit for soil; MP Biomedicals, Solon, OH, United States) to extract the total community DNA. The frozen samples were directly transferred into the extraction vials provided in the kit mentioned earlier to avoid contaminations during handling. Subsequently, all total community DNA extractions were conducted according to the manufacturer's protocol. The extracts were photometrically analyzed with a Nanodrop 2000 device (Thermo Fisher Scientific, Wilmington, DE, United States) to quantify the DNA and verify its quality; 12 biological replicates were obtained with sufficient DNA concentrations for the subsequent steps. The total community DNA extracts were stored at $-20^{\circ} \mathrm{C}$ until further processing.

\section{Barcoding and High-Throughput Sequencing of 16S Ribosomal RNA Gene Fragment Amplicons}

The DNA samples mentioned earlier were sent to a sequencing company (Novogene Co., Ltd., Beijing, China) for nextgeneration sequencing that targeted the hypervariable region 4 (V4) of bacterial 16S rRNA genes. The samples were amplified with the primers 515f (5'GTGYCAGCMGCCGCGGTAA) and 806r (5'GGACTACHVGGGTWTCTAAT) according to the Earth Microbiome Project protocol $^{1}$ with sample-specific barcodes and Illumina sequencing adaptors. The following polymerase chain reaction (PCR) program $\left(95^{\circ} \mathrm{C}\right.$ for $5 \mathrm{~min}$ to denature the DNA, 30 cycles at $96^{\circ} \mathrm{C}$ for $60 \mathrm{~s}, 78^{\circ} \mathrm{C}$ for $5 \mathrm{~s}, 54^{\circ} \mathrm{C}$ for $60 \mathrm{~s}, 74^{\circ} \mathrm{C}$ for $60 \mathrm{~s}$, and $10 \mathrm{~min}$ at $74^{\circ} \mathrm{C}$ for a final extension) was used for the generation of amplicons according to a method described before (Thompson et al., 2017). During the PCR amplification, specific peptide nucleic acid (PNA) oligomers were added to the PCR mix to prevent the amplification of mitochondrial (mPNA) or plastidial (pPNA) RNA from eukaryotic origin (Lundberg et al., 2013). The PCR blockers were obtained from PNA Bio Inc. (Newbury Park, CA, United States). Negative controls were included in each PCR reaction. They did not result in visible products and were thus not subjected to sequencing to avoid misassignments due to "index hopping" in low-quantity DNA samples (Van der Valk et al., 2020). High-throughput sequencing was conducted by Novogene (Beijing, China) on the Illumina PE250 platform that produces $2 \times 250$-bp paired-end reads.

\section{Bioinformatic Processing of the 16S Ribosomal RNA Gene Fragment Library}

The reads were assigned to samples by demultiplexing them according to their unique barcode sequences. All demultiplexed paired-end reads were imported into QIIME2 2019.10 (Bolyen et al., 2019) and quality-filtered using the q2-demux plugin followed by denoising with DADA2 (Callahan et al., 2016) (with the q2-dada2 plugin) to summarize sequence variants (SVs) and to generate a filtered feature table as well as representative sequences. The chimeras were filtered from the table, and taxonomy was assigned to amplicon sequence variants (ASVs) using the q2-feature classifier (Bokulich et al., 2018) in combination with "Greengenes 13_8 99\% ASVs" reference sequences (McDonald et al., 2012). Subsequently, the determination of alpha and beta diversity was performed using the QIIME 2 core diversity metrics and group significance tests using the q2-diversity plugin (Faith, 1992) after samples were rarefied to 66,246 reads per sample. The feature table was split into four separate tables according to the sample

\footnotetext{
${ }^{1}$ www.earthmicrobiome.org
} 
group (cabbage-fed, pepper-fed, eggplant-fed, and tobaccofed). For visualization, the feature table was exported from QIIME2, and barplots were generated with a cut-off of $0.1 \%$ abundance. Significant differences in the occurrence of distinct ASVs between the control and each treatment were calculated using the $\mathrm{R}$ (version 4.03) package edgeR (version 3.30.3) (Robinson et al., 2010).

\section{Verification of Pseudomonas and Buchnera Enrichment in the Samples}

To confirm changes in the abundance of the genera Pseudomonas and Buchnera when $M$. persicae was fed with different plant diets, a quantitative PCR (qPCR)-based approach was used. The same samples used to generate the amplicon library were also used to quantify Pseudomonas and Buchnera in the DNA extracts. All samples were adjusted to a concentration of $2 \mathrm{ng} / \mu \mathrm{l}$ according to quantifications with a Nanodrop 2000 (Thermo Fisher Scientific, Wilmington, DE, United States) to account for the differences in the extraction efficiency and subsequently used for molecular quantifications with a CFX96 Real-Time System (Bio-Rad Laboratories, Hercules, CA, United States). Each sample was analyzed with four technical replicates. The primer pair used for Pseudomonas quantification was Pse434F (5'-ACTTTAAGTTGGGAGGAAGGG-3') and Pse665R (5'-ACACAGGAAATTCCACCACCC-3') (Pereira et al., 2018). The primer pair used for Buchnera quantification was dnaK2F (5'-GATTGTCTTCGGCTGTTG-3') and dnaK2R $\left(5^{\prime}\right.$-GTCACTCCTTTATCACTTGG- $\left.3^{\prime}\right)$. In addition, the aphid's elongation factor $1 \alpha$ (using primers AWRT002F $5^{\prime}$-CTGATTGTGCTGTGCTTATTG- $3^{\prime}$ and AWRT002R 5' CAAGGTGAAAGCCAATAGAGC-3') (Jiang et al., 2013) was included in the quantifications as a reference gene. The total reaction volume was $20 \mu \mathrm{l}$ and contained 10- $\mu$ l PowerUp SYBR Green Master Mix (Applied Biosystems, Vilnius, Lithuania), 1- $\mu$ l DNA template, $1-\mu \mathrm{l}(5-\mathrm{nM})$ forward primer, $1-\mu \mathrm{l}(5-\mathrm{nM})$ reverse primer, and 7- $\mu \mathrm{l}$ sterile ddH2O. The PCR cycling conditions for Pseudomonas quantification included an initial denaturation at $95^{\circ} \mathrm{C}$ for $5 \mathrm{~min}$, followed by 40 cycles of $95^{\circ} \mathrm{C}$ for $20 \mathrm{~s}, 60^{\circ} \mathrm{C}$ for $20 \mathrm{~s}$, and $72^{\circ} \mathrm{C}$ for $25 \mathrm{~s}$. The PCR cycling conditions for Buchnera quantification included an initial denaturation at $95^{\circ} \mathrm{C}$ for $5 \mathrm{~min}$, followed by $45 \mathrm{cycles}$ at $95^{\circ} \mathrm{C}$ for $20 \mathrm{~s}, 57^{\circ} \mathrm{C}$ for $20 \mathrm{~s}$, and $72^{\circ} \mathrm{C}$ for $25 \mathrm{~s}$. For quantification of the aphid's elongation factor $1 \alpha$, the initial denaturation was conducted at $95^{\circ} \mathrm{C}$ for $5 \mathrm{~min}$, followed by 40 cycles at $95^{\circ} \mathrm{C}$ for $20 \mathrm{~s}, 59^{\circ} \mathrm{C}$ for $20 \mathrm{~s}$, and $72^{\circ} \mathrm{C}$ for $25 \mathrm{~s}$. A melting curve $\left(68-95^{\circ} \mathrm{C}\right)$ was obtained in the final step for all three approaches. The cycle threshold was used as a reference to validate differences in the abundance of Pseudomonas and Buchnera in M. persicae grown on different plant diets.

\section{Isolation of Bacteria From Guts of M. persicae and Susceptibility Testing Toward Nicotine}

Aphids were randomly collected from the four host plants and dissected as described earlier to obtain aphid 50 guts per sample. After grinding the guts using an automated tissue grinding device (BBI Life Sciences, Shanghai, China) for $5 \mathrm{~s}$, the guts were transferred into $10 \%$ nutrient broth and incubated at $30^{\circ} \mathrm{C}$ on a shaker at $180 \mathrm{rpm} / \mathrm{min}$ for $12 \mathrm{~h}$. Subsequently, a micropipette was used to transfer $10-\mu l$ bacterial suspension after dilution with $0.85 \% \mathrm{NaCl}\left(10^{-1}-10^{-3}\right.$ dilutions) to Petri dishes with LB agar, nutrient agar, and R2A agar. The plates were cultivated at $30^{\circ} \mathrm{C}$ until the appearance of bacterial colonies. For Pseudomonas isolations, Pseudomonas isolation broth was used to incubate 50 guts that were dissected from cabbage- and Solanaceae-fed aphids. Incubations were performed at $30^{\circ} \mathrm{C}$ on a shaker at $180 \mathrm{rpm} / \mathrm{min}$ for $12 \mathrm{~h}$. Diluted suspensions $\left(10^{-1}\right.$ $10^{-3}$ dilutions) were then transferred to Pseudomonas CFC selective agar (Qingdao Hope Bio-Technology Co., Ltd.) with Pseudomonas CFC selective agar supplement (Qingdao Hope Bio-Technology Co., Ltd.) and to King's B medium (Qingdao Hope Bio-Technology Co., Ltd.). They were cultivated at $30^{\circ} \mathrm{C}$ until bacterial colonies appeared, which were subsequently purified. The bacterial genomic DNA extraction kit (Beijing Solarbio Science \& Technology Co., Ltd.) was used to extract the DNA of all isolates before PCR amplification of 16S rRNA gene fragments for taxonomic identification with the primer pair 27F (5'-AGAGTTTGATCCTGGCTCAG-3') and 1492r (5'-GGTTACCTTGTTACGACTT- $3^{\prime}$ ). The PCR amplification comprised an initial cycle at $95^{\circ} \mathrm{C}$ for $2 \mathrm{~min}$, followed by 34 cycles of denaturation at $95^{\circ} \mathrm{C}$ for $30 \mathrm{~s}$, annealing at $50^{\circ} \mathrm{C}$ for $1 \mathrm{~min}$, extension at $72^{\circ} \mathrm{C}$ for $2 \mathrm{~min}$, and a final extension step at $72^{\circ} \mathrm{C}$ for $10 \mathrm{~min}$. The length of PCR products was confirmed by $1 \%$ gel electrophoresis, and the PCR products were sent to Sangon Biotech (Shanghai, China) for Sanger sequencing. Based on the obtained 16S rRNA gene fragment sequences, phylogenetic placement was conducted. The candidate taxa for the phylogenetic analysis included all isolates from aphid guts and such with high similarities in BLAST searches within the National Center for Biotechnology Information (NCBI) nucleotide database. To construct a phylogenetic tree with those sequences, multiple alignments were performed using Clustal W (Thompson et al., 1994). Subsequently, molecular phylogenetic analyses based on neighbor-joining algorithms were created with MEGA7 (Kumar et al., 2016). Bootstrap values were calculated with 1,000 replications for the neighbor-joining method.

All isolates were additionally subjected to susceptibility testing toward nicotine, a bioactive metabolite characteristic of Solanaceae plants. Bacteria were cultivated on nutrient medium and R2A medium (for slow-growing bacteria) to obtain single colonies. Sterile toothpicks were used to transfer single colonies to the nutrient broth and liquid R2A medium, followed by incubation for $16 \mathrm{~h}$ at $30^{\circ} \mathrm{C}$ and $180 \mathrm{rpm} / \mathrm{min}$. Subsequently, the bacterial suspensions were diluted to an optical density measured at a wavelength of $600 \mathrm{~nm}$ of 0.1 in a liquid R2A liquid medium. Aliquots of $5 \mathrm{ml}$ were transferred into glass test tubes $(18 \times 180 \mathrm{~mm})$ with $0,2,4$, and $8 \mathrm{~g} / \mathrm{l}$ nicotine passed through a $0.22-\mu \mathrm{m}$ PES filter (Tianjin Keyilong Lab Equipment Co., Ltd) for sterilization. The glass test tubes were incubated in a shaker at $30^{\circ} \mathrm{C}$ and $160 \mathrm{rpm} / \mathrm{min}$. The optical density measured at a wavelength of $600 \mathrm{~nm}$ was then recorded each $6 \mathrm{~h}$ for $48 \mathrm{~h}$ with the Multiskan GO instrument (Thermo Fisher Scientific, Vantaa, Finland) to monitor bacterial growth in a nicotine-supplemented medium. 


\section{Statistical Analyses}

Statistical tests for the microbiome analyses were performed using the QIIME 2 and $\mathrm{R}$ studio ( $\mathrm{R}$ version 4.03) software packages. The significance of the differences in alpha diversity was tested with the implemented Kruskal-Wallis test and for the beta diversity with the analyses of similarities test in the QIIME 2 pipeline. The $\mathrm{R}$ package edge $\mathrm{R}$ was implemented to identify differently abundant genera between the treatments $\left(\log _{2}\right.$ fold change $>2$ and $\log _{2}$ fold change $<-2 ; P<0.01$ ). The statistical significance of the differences in the $\mathrm{qPCR}$ data was assessed with the Kruskal-Wallis test.

\section{RESULTS}

\section{Alpha and Beta Diversity Analyses of the Aphid Microbiome Under Different Plant Diets}

After filtering chimeric, mitochondrial, and plastid sequences, the feature table was reduced from a total read count of 6,200,722 to $5,310,692$, representing 20,876 features. Data normalization resulted in a read count of 66,246 per sample; a total number of 20,111 features remained in the dataset. Collapsing features on genus level resulted in 1,607 bacterial genera and 37 archaeal taxa. The Shannon index (Figure 1A) was used to compare the bacterial diversity among the different samples. The microbiomes of cabbage-fed aphids $\left(H^{\prime}=2.21 \pm 0.27\right)$, eggplant-fed aphids $\left(H^{\prime}=2.41 \pm 0.28\right)$, and tobacco-fed aphids $\left(H^{\prime}=3.05 \pm 0.56\right)$ had a significantly lower alpha diversity than pepper-fed aphids $\left(H^{\prime}=5.88 \pm 0.78 ; P<0.05\right)$. There were no significant differences between the other groups $(P>0.05)$. Similar results were obtained when the number of observed ASVs (Figure 1B) was compared between cabbage-fed aphids (observed ASVs $=544 \pm 80$ ), eggplant-fed aphids (obs. ASVs $=560 \pm 65$ ), tobacco-fed aphids (obs. ASVs $=845 \pm 108)$, and pepper-fed aphids (obs. ASVs $=1,163 \pm 180$ ). Significant differences were found when cabbage-fed aphids and eggplantfed aphids were compared with pepper-fed aphids $(P<0.05)$, whereas no significance was observed between pepper-fed aphids and tobacco-fed aphids $(P>0.05)$. Beta diversity analyses revealed distinct clustering of sample groups based on Bray-Curtis dissimilarities (Figure 2). Analyses of similarities confirmed highly significant $(R=0.5 ; P=0.001)$ differences in community composition between the cabbage-fed and the Solanaceae-fed aphids.

\section{Assessment of the Bacterial Community Structure and Composition}

At the bacterial family level, the cabbage-fed aphids were primarily colonized by Enterobacteriaceae (68.2\%), Moraxellaceae (7.9\%), Erysipelotrichaceae (5.3\%), and Rickettsiaceae (4.7\%; Figure 3). The prevalent bacterial genera were identified as Buchnera (67.7\%), Acinetobacter (7.8\%), and Allobaculum (5.3\%). The eggplant-fed aphids were mainly colonized by the bacterial families Pseudomonadaceae (69.5\%), Enterobacteriaceae (13.4\%), Oxalobacteraceae (2.4\%), and Burkholderiaceae (1.8\%). Pseudomonas (69.4\%), Buchnera (12.5\%), Ralstonia (2.1\%), and Burkholderia (1.7\%) were the most common genera in the eggplant-fed aphids. In tobacco-fed aphids, Pseudomonadaceae (62.3\%), Enterobacteriaceae (15.9\%), Oxalobacteraceae (3.2\%), and Burkholderiaceae (2.2\%) were the prevalent taxonomic groups on the bacterial family level. Pseudomonas (62.2\%) was the predominant genus, followed by Buchnera (14.6\%), Ralstonia (3.0\%), and Burkholderia (2.1\%). In the pepper-fed aphids, Enterobacteriaceae (29.3\%) was the most prevalent bacterial family, whereas Pseudomonadaceae (11.8\%) and Oxalobacteraceae (9.3\%) were less abundant, followed by Burkholderiaceae (5.1\%). The predominant genus in pepper-fed aphids was Buchnera (25.5\%). The second most abundant genus was Pseudomonas (11.7\%), followed by Ralstonia (8.4\%), Burkholderia (5.0\%), Enterobacteriaceae (3.2\%), Acinetobacter $(2.3 \%)$, and Stenotrophomonas (1.7\%). Notably, the pepper plant diet not only showed the least increase in the abundances
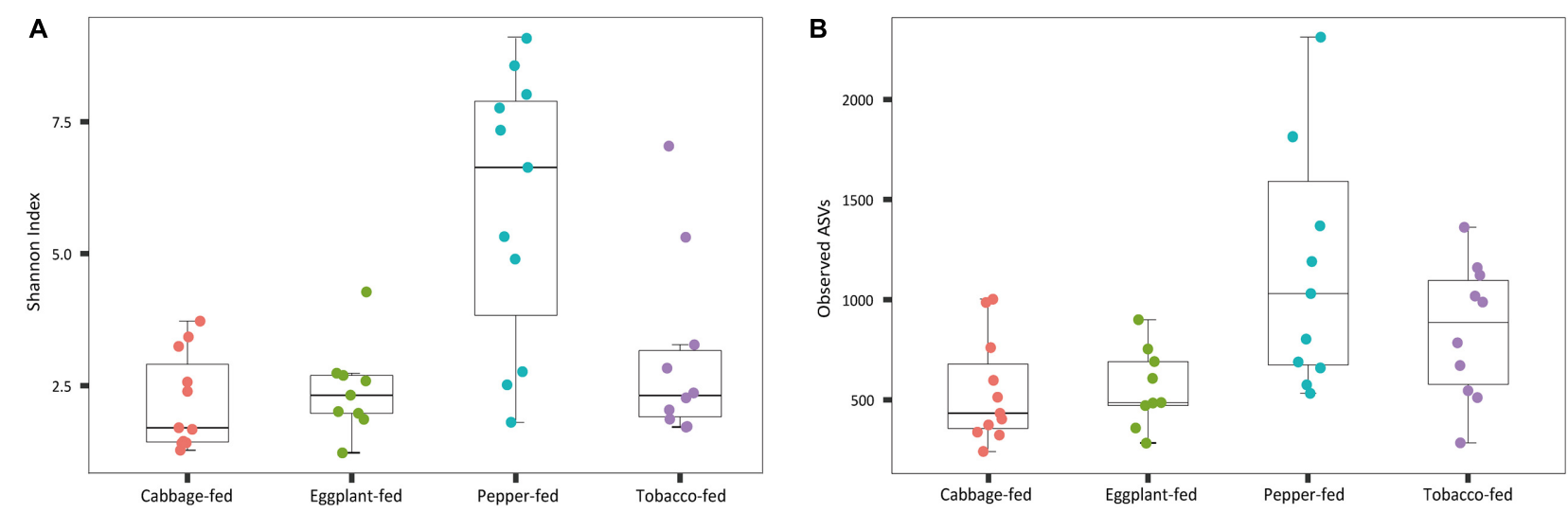

FIGURE 1 Alpha diversity of bacterial communities in Myzus persicae subjected to different plant diets. Diversity was assessed within the QIIME2 pipeline on basis of Shannon index (A) and observed operational taxonomic units (ASVs) (B) in the normalized dataset. All samples were rarefied to a sequence depth of 66,246 reads before being subjected to diversity analyses. 

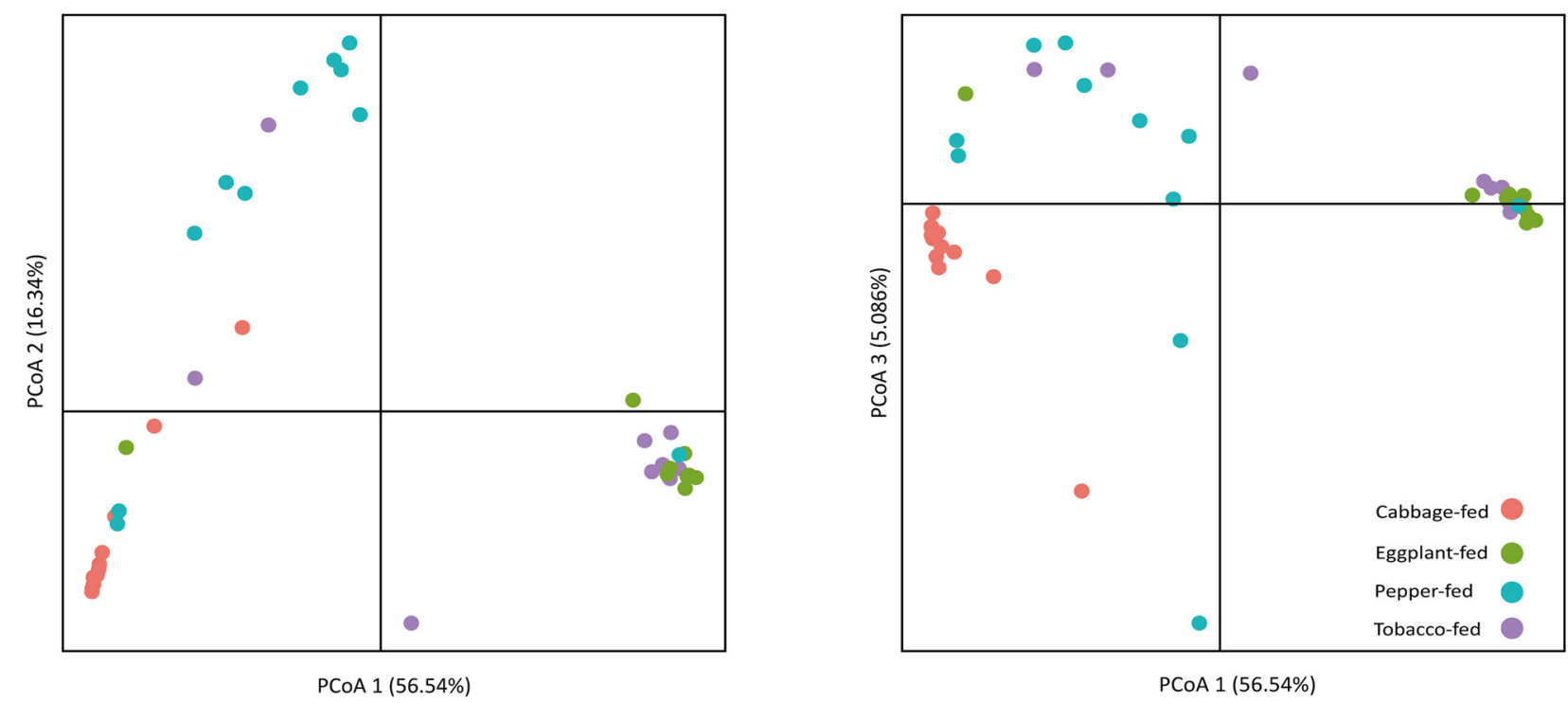

FIGURE 2 | Principal coordinates analysis (PCoA) of bacterial community structure in cabbage-fed and Solanaceae-fed aphids. Three dimensions that explain highest degree of variance were included in visualization. Percentage variance explained is indicated on respective axes. Different colors of dots indicate different sample types. Significance of differences between different bacterial communities was tested with ANOSIM in QIIME 2.

of Pseudomonas and the least decrease in the abundance of Buchnera but also other changes in the microbiome when compared with the other two Solanaceae plants. Several lowabundant members of the Gram-positive bacterial phylum Firmicutes increased under the pepper diet, which reflects the previously observed differences in alpha and beta diversity (Figures 1, 2).

\section{Identification of Bacteria That Were Significantly Affected by the Diet}

In addition to the general analysis of the microbiome in differently fed aphids, deepening statistical analyses based on edge $\mathrm{R}$ were conducted to identify differentially abundant taxa in each of the treatment groups (Figure 4 and Supplementary Dataset 1). Taxa that were significantly more abundant in eggplant-fed aphids included Pseudomonas (12 features), Staphylococcus (three features), Serratia, Rhodoplanes, Thermotoga, Rubellimicrobium, Acinetobacter, and unassigned bacteria (12 features). Forty-six features were shown to be depleted when eggplant-fed aphids were compared with cabbagefed aphids (Figure 4A). In pepper-fed aphids, Psychrobacter, Phormidium, Comamonas, Sporosarcina, Pseudomonas, Ruminococcus (three features), and unassigned bacteria (three features) were enriched. In contrast, 61 features were enriched in cabbage-fed aphids when compared with pepper-fed aphids (Figure 4B). In the tobacco diet group, 21 features were more abundant than in the cabbage group and assigned to Dokdonella, Dok59, Methylibium, Nitrosopumilus, Pseudomonas (five features), Acinetobacter, and unassigned bacteria (11 features). The remaining 81 features were found to be enriched in cabbage-fed aphids (Figure 4C). When all groups were comparatively assessed, Pseudomonas was found to be enriched in all Solanaceae-fed aphids, whereas 21 genera were depleted in those aphids when compared with cabbage-fed aphids. The depleted genera were assigned to Buchnera, Wolbachia, Helicobacter, Acinetobacter, Actinoplanes, Adlercreutzia, Alicyclobacillus, Allobaculum, Chitinophaga, Coprococcus, Dyadobacter, Lysobacter, Lactobacillus, Microbacterium, Mucispirillum, Oscillospira, Paracoccus, Promicromonospora, Ruminococcus, Staphylococcus, and Streptomyces (Figure 4).

\section{Quantitative Polymerase Chain Reaction Confirmed Relative Enrichment of Pseudomonas and Depletion of Buchnera}

As a complementary approach to the marker gene sequencing analyses, the abundance of Pseudomonas and Buchnera was confirmed by qPCR targeting these taxa in the total community DNA extracts (Figure 5). The conducted Kruskal-Wallis test for the cycle thresholds indicated that Pseudomonas was significantly increased in eggplant-fed aphids $(\mathrm{Cq}=25.9 \pm 0.6)$ and tobaccofed aphids $(\mathrm{Cq}=25.4 \pm 0.8 ; P<0.01)$ when compared with cabbage fed aphids $(\mathrm{Cq}=30.1 \pm 0.1)$. However, the difference between pepper-fed aphids $(\mathrm{Cq}=29.8 \pm 0.5)$ and cabbagefed aphids $(\mathrm{Cq}=30.1 \pm 0.4 ; P=0.7903)$ was not significant. Buchnera showed a significant decline in eggplant-fed aphids $(\mathrm{Cq}=33.9 \pm 0.8)$, pepper-fed aphids $(\mathrm{Cq}=32.2 \pm 0.6)$, and tobacco-fed aphids $(\mathrm{Cq}=31.9 \pm 0.7 ; P<0.01)$. The overall results reflected the observations of the microbiome analyses, especially in the substantial reduction of Buchnera in Solanaceaefed aphids. A complementary quantification of the aphid's elongation factor $1 \alpha$ in total community DNA extracts indicated that the host-microbe DNA proportion was similar among 


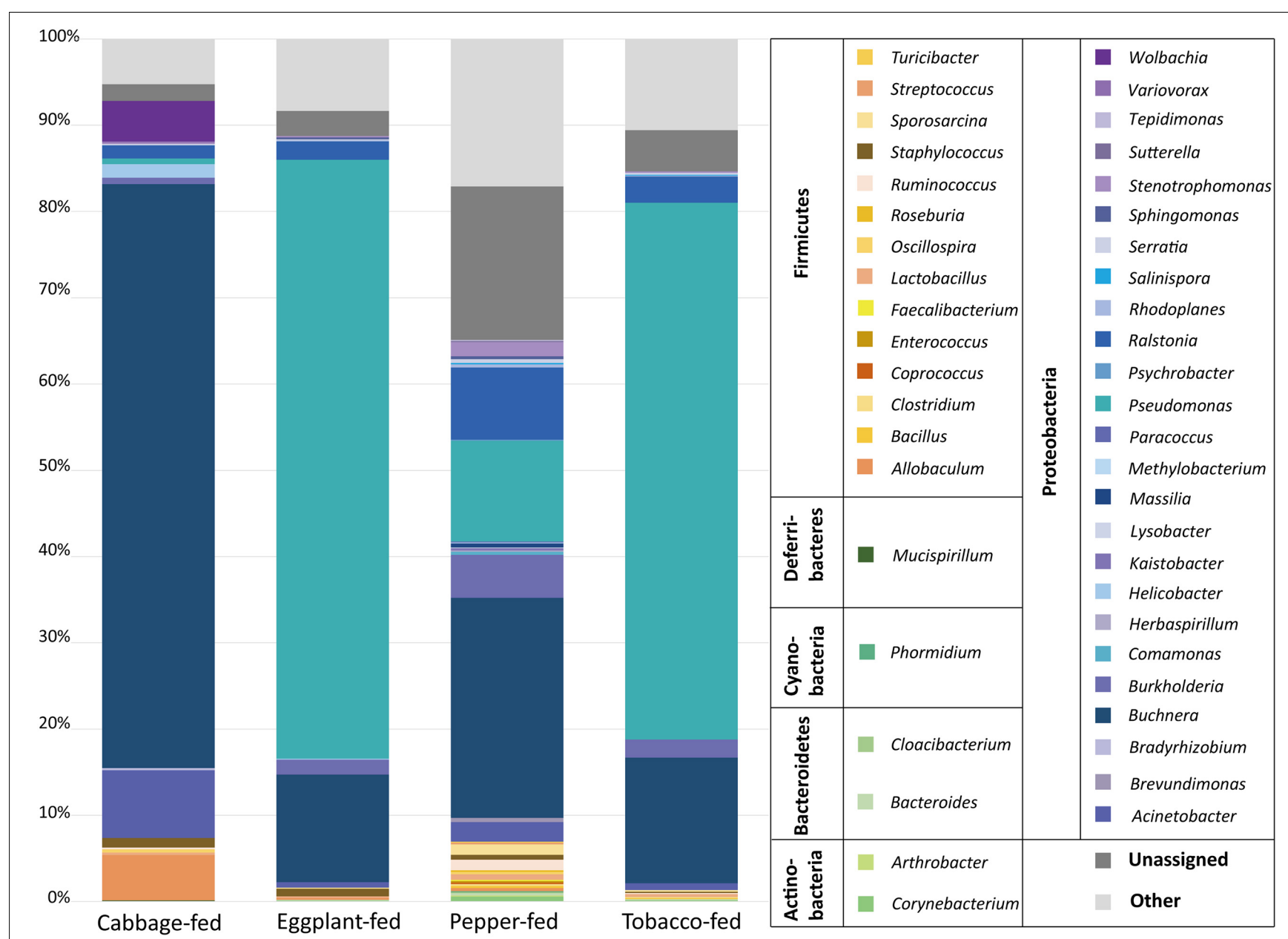

FIGURE 3 | Bacterial community structure of different sample types. Taxonomic classification of highly abundant (>0.1\%) members of aphid microbiome on different diets. Taxa with a lower abundance than the implemented threshold were summarized as "other." Bacterial community structure was visualized up to genus level for each sample type. In addition, all taxa were grouped on bacterial phylum level in legend for better differentiation.

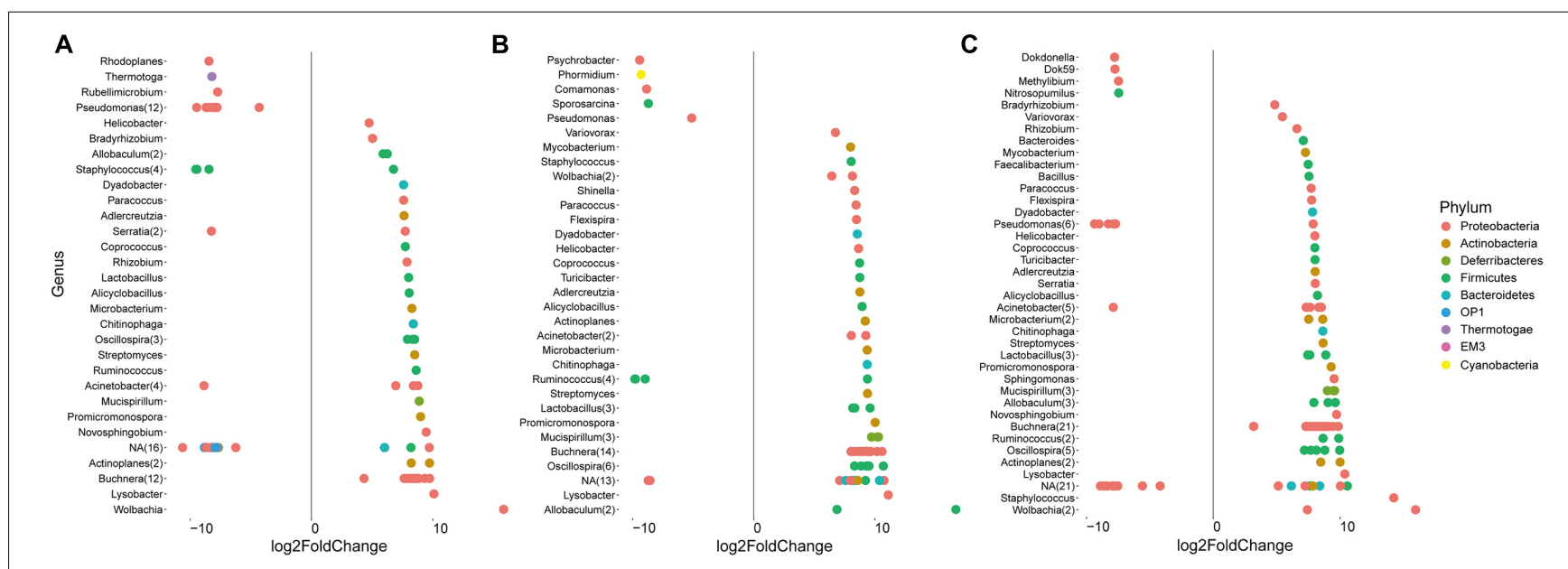

FIGURE 4 | Identification of amplicon sequencing variants (ASVs) that differ significantly in their relative abundance among treatments. Pairwise comparisons were conducted for Solanaceae-fed aphids and cabbage-fed aphids using edegR tool $(P<0.01)$. (A) Comparison of cabbage-fed aphids with eggplant-fed aphids; (B) comparison of cabbage-fed with pepper-fed aphids; (C) comparison of cabbage-fed aphids with tobacco-fed aphids. Taxonomy of ASVs was assigned at bacterial genus level whenever it was possible. 

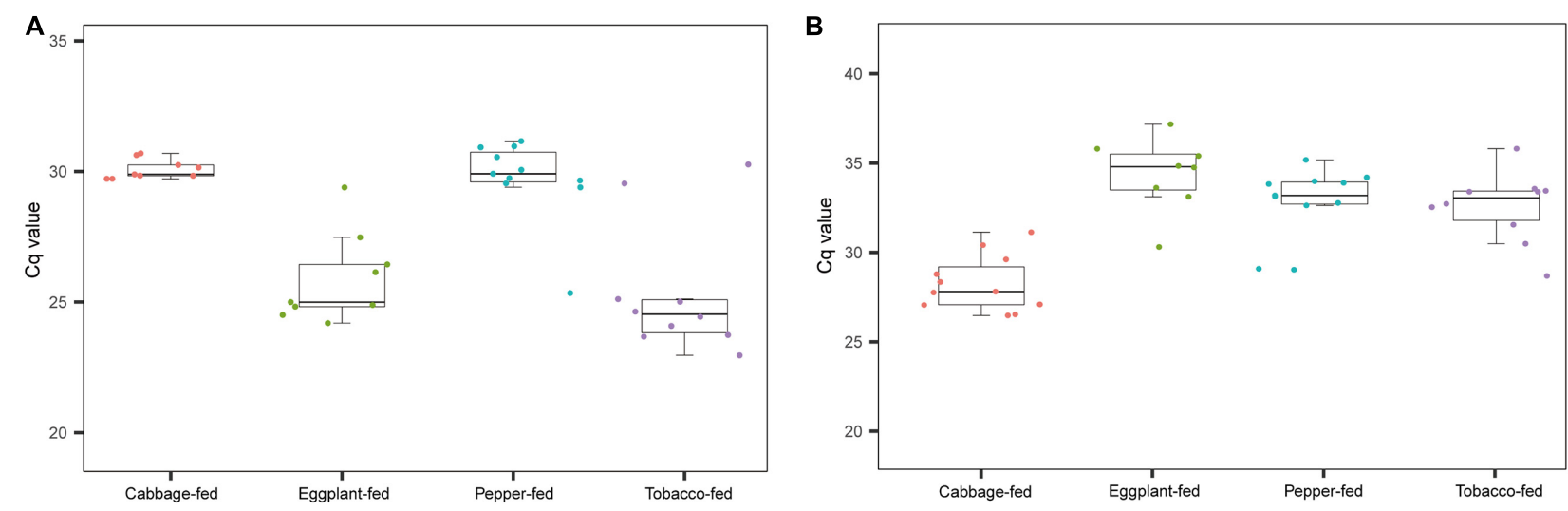

FIGURE 5 | Complementary molecular quantifications of changes in relative abundance of Pseudomonas and Buchnera in aphids on different plant diets. Enrichment of Pseudomonas and depletion of Buchnera in Solanaceae-fed aphids was confirmed with a complementary qPCR-based approach and genus-specific detection primers. (A) Cq values of Pseudomonas in gut of $M$. persicae fed with different plants; (B) Cq values of Buchnera fed with different plants.

all sample groups (Supplementary Figure 3). Complementary analyses of $M$. persicae population dynamics on different hosts indicated that it was only negatively affected following the transition to pepper plants (Supplementary Figure 4).

\section{Isolation of Bacteria From M. persicae and Their Phylogenetic Placement}

To obtain complementary insights into the observations of the microbiome analysis, isolation of gut bacteria on different cultivation media was conducted. Guts of $M$. persicae aphids feeding on cabbage, eggplant, pepper, and tobacco were dissected, and a total of 16 isolates was obtained using LB agar, nutrient agar, R2A agar, Pseudomonas CFC selective agar, and King's B medium. Five bacterial strains were isolated from aphids reared on the cabbage diet and assigned to Curtobacterium citreum, Brevibacterium sediminis, Microbacterium esteraromaticum, Microbacterium proteolyticum, and Pseudomonas reactans. Six strains were isolated from aphids fed with tobacco and assigned to B. sediminis, Methylorubrum aminovorans, M. esteraromaticum, Exiguobacterium indicum, Pseudomonas brenneri, and $P$. reactans. Three strains that were respectively assigned to Microbacterium paraoxydans, $P$. reactans, and $P$. brenneri were isolated from aphids fed with eggplant. Bacillus indicus and $P$. reactans were isolated from aphids that were fed with pepper. The isolates were used for phylogenetic placements based on their 16S rRNA gene fragments (Figure 6). All isolates showed a high similarity to sequences deposited in the NCBI nucleotide database, indicating that the cultivable fraction of the $M$. persicae microbiome consists of bacteria that were previously described.

\section{Susceptibility Testing of Bacterial Isolates Toward Nicotine}

Isolated bacteria from guts of $M$. persicae growing on four plants diets were subjected to specific susceptibility tests. To assess the susceptibility of bacteria toward nicotine, their growth in medium with $0,2,4$, and $8 \mathrm{~g} / \mathrm{l}$ nicotine was monitored for $48 \mathrm{~h}$
(Supplementary Figure 5). According to the results of a twofactor analysis of variance, the growth rate of all bacterial was significantly reduced with an increasing concentration of nicotine or even completely restrained $(P<0.01)$. M. aminovorans strain T2 was not able to grow in any medium supplemented with nicotine. C. citreum strain C3, M. proteolyticum strain C4, $P$. reactans strain C-P, E. indicum strain T4, $P$. brenneri strain T-P1, P. brenneri strain T-P2, M. paraoxydans strain E2, $P$. reactans strain E-P1, $P$. brenneri strain E-P2, and $P$. reactans strain P-P were not able to grow in medium supplemented with $8 \mathrm{~g} / \mathrm{l}$ nicotine. Isolates that were able to grow in medium supplemented with $8 \mathrm{~g} / \mathrm{l}$ nicotine included the $B$. sediminis strain $\mathrm{C} 1$ and $M$. esteraromaticum strain $\mathrm{C} 2$ that were obtained from cabbage-fed aphids, two isolates from tobacco-fed aphids (B. sediminis strain $\mathrm{T} 1$ and $M$. esteraromaticum $\mathrm{T} 3$ ), and the $B$. indicus strain $\mathrm{P}$ that was isolated from pepper-fed aphids.

\section{DISCUSSION}

By assessing the changes in the bacterial community of $M$. persicae fed with three Solanaceae plants (eggplant, pepper, and tobacco) and cabbage as a reference treatment, we could mechanistically confirm that the microbiome of aphids is influenced by the plant diet. This is in line with recent findings of $\mathrm{Xu}$ et al. (2019) that assessed the microbiome of Aphis gossypii (Hemiptera: Aphididae) and found clear indications that it was affected by its host plants. In contrast, previous field studies conducted with $M$. persicae feeding on different plants did not show significant differences in the aphid's microbiome composition (Xu S. et al., 2021). This is most likely due to the described migration of the aphids. In the present study, this factor was excluded by conducting feeding experiments under controlled conditions. The present study provides indications that the microbiome of $M$. persicae can be substantially shaped by the host plant and that these changes take place within a short period. More in-depth studies will be needed in the future to assess whether these changes are temporary or whether they 


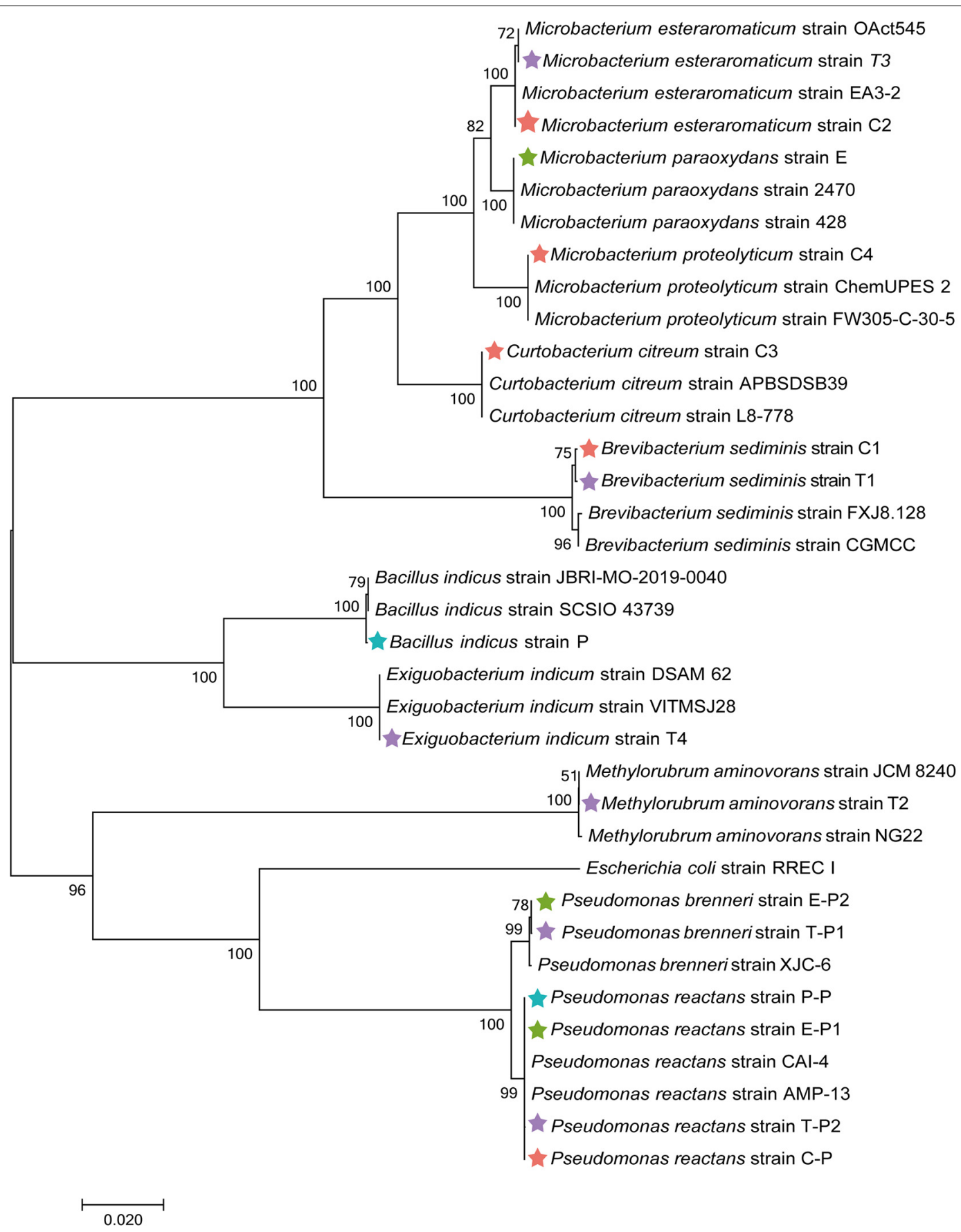

FIGURE 6 | Phylogenetic placement of isolated bacteria based on their 16S rRNA gene fragment sequences. Neighbor-joining method in MEGA7 with 1,000 bootstrapping replications was used to generate phylogenetic tree. Highly matching sequences of bacteria from public nucleotide databases were included; Escherichia coli RREC I was used as an outgroup. Isolates from cabbage-fed aphids are labeled with red stars, eggplant-fed aphids with green stars, pepper-fed aphids with blue stars, and tobacco-fed aphids with purple stars.

manifest in subsequent generations. For this purpose, targeted studies could be conducted in which aphids are transferred back to the original host plant, followed by microbiome monitoring.

Overall, we found that even if the aphids were fed with different plants, Buchnera still remained as the most abundant primary symbiont in $M$. persicae guts and the attached bacteriocytes; however, it was substantially reduced after the transfer to Solanaceae hosts. Buchnera is known for its importance as the primary symbiont of various insects and is commonly inherited from mother to offspring (Baumann et al., 1995). We hypothesize that Buchnera was substantially reduced after the transition of aphids to the three Solanaceae hosts either 
because the plants' secondary metabolites had a negative effect on it or they provided more suitable conditions for its competitors. This observation was confirmed by complementary qPCR analyses, which showed analogous trends when compared with the microbiome results. The implications of nutrient provision by primary symbionts of insects are well known (Moran et al., 2003; Akman Gündüz and Douglas, 2009). It can therefore be assumed that a temporally reduced occurrence of the primary symbiont, at least in the gut and the attached bacteriocytes, does not negatively affect the host. Interestingly, pepper-fed aphids showed a different bacterial community composition than the other two Solanaceae-fed aphids. The most evident difference was a lower increase of the genus Pseudomonas represented by one ASV, whereas the other two Solanaceae-fed aphids showed higher increases represented by multiple ASVs. Moreover, Pseudomonas was found to occur at very low abundances in cabbagefed aphids $(0.6 \%)$, but it substantially increased (maximum observed abundance: $69.4 \%$ ) after the transition to Solanaceaebased diets. Complementary qPCR-based analyses confirmed a substantial enrichment in tobacco-fed and eggplant-fed aphids, whereas the aphids subjected to the pepper diet showed a comparatively lower enrichment of quantifiable Pseudomonas sequences in the total community DNA extracts. This is in line with the microbiome profiles that were generated with the high-throughput sequencing approach. Some Pseudomonas species are known to be pathogens (Flury et al., 2016), whereas others have beneficial traits, and some are even commercialized for certain applications in agriculture (Kupferschmied et al., 2013). In addition, various Pseudomonas species are associated with crop plants and can occur in different tissues and the plant rhizosphere. Some were found to be important elicitors of induced systemic resistance in plants (Kloepper et al., 2004). When plants are under attack by pathogens or insect pests, they can recruit beneficial pseudomonads for their defense (Lee et al., 2012). A previous study indicated that certain plant-beneficial Pseudomonas strains could improve the growth of feeding aphids under certain conditions (Blubaugh et al., 2018). The substantial enrichment of Pseudomonas in $M$. persicae observed in the present study may be partially due to uptake from host plants. We could also show that some pseudomonads are naturally occurring in the aphid's gut, although at substantially lower abundances if they are not subjected to a Solanaceae-based diet. Further future studies will be required to determine the proportion of bacteria transferred from the host plant to the feeding aphids. They will require additional sequencing of the plant leaf microbiome before exposure to aphids. A study by Stavrinides et al. (2009) showed that Pseudomonas syringae could use pea aphids as hosts and vectors to infect other plants. Pseudomonas was generally shown to be a highly efficient colonizer of insect hosts (Lindeberg et al., 2008). In a recent study, it has been shown that certain members of this genus can change from a commensal to a pathogenic lifestyle in the gut of insects (Xu L. et al., 2021). Our findings indicate that Pseudomonas may play a role in the adaption of aphids to new host plants. This observation is reinforced by our complementary analysis of population dynamics, which revealed that only bell pepper plants in which the smallest increases in Pseudomonas abundance were found negatively affected aphids. The microbiome of aphids fed with pepper plants was also characterized by an increase of low-abundant members of the bacterial phylum Firmicutes. The genera Sporosarcina and Ruminococcus have significantly enriched these aphids. Members of the genus Sporosarcina are occurring in the environment and are known for their bioremediation potential (Achal et al., 2012), whereas Ruminococcus is mainly associated with the gut system of mammals (La Reau et al., 2016). Less is known about their potential roles in insects. The underlying mechanisms of the diet-induced microbiome changes and the potentially linked implications for host fitness remain to be explored in more detail in the future because they may provide an exploitable basis for the control of $M$. persicae and other insect pests. In addition to the increased abundance of Pseudomonas and decrease of Buchnera in Solanaceae-fed aphids, another bacterium that is commonly associated with insects was also subjected to changes. Wolbachia is generally known to be less abundant in aphids than the predominant Buchnera but can also occur as a symbiont (Augustinos et al., 2011). In the present study, Wolbachia followed the same trend as Buchnera; a substantial decrease in its relative abundance was observed after the aphid's transition to Solanaceae plants. Based on the observations of this study, it seems that this reduction also does not negatively affect the host.

As a complementary approach to the bioinformatics analyses, we also aimed to assess parts of the cultivable fraction in the present study to explore potential links to their tolerance of a bioactive metabolite common in the Solanaceae plant family. Nicotine has strong insecticidal properties and is used in different formulations for plant protection (Casanova et al., 2002). It was previously observed that $M$. persicae could adapt to high nicotine concentrations in host plants (Ramsey et al., 2014). Although certain genes are associated with detoxification processes in the aphid, other mechanisms remained unexplored. To assess the potential roles of facultative symbionts isolated from $M$. persicae guts, we conducted tolerance assays with nicotine. Nicotine is generally known to have toxic and pharmacological properties and thus affects a wide range of organisms, including bacteria (Hossain and Salehuddin, 2013; Vieira et al., 2013). We could show that several bacterial strains isolated from aphid guts displayed a high nicotine tolerance under laboratory conditions. Various facultative symbionts are not required for aphid survival, reproduction, and invasion, but they can still play important roles in their host (Oliver et al., 2010). For instance, facultative symbionts can affect the aphid's adaptability to plants, and they can improve nutrient uptake of their host among various other protective properties (Russell and Moran, 2006; Oliver et al., 2010; Tsuchida et al., 2010; Gauthier et al., 2015). The susceptibility tests toward nicotine showed that the isolated bacteria tolerated the toxic metabolite to different extents. With the increasing nicotine concentrations, the growth rate of all tested bacteria decreased. M. aminovorans (basionym: M. aminovorans) strain T2 was an exception; it was already inhibited by low nicotine concentrations, although it was isolated from aphids feeding on tobacco. Methylobacteria are nonspore-forming bacteria and form Gram-negative rods that can utilize methanol and often other small hydrocarbons for their growth Urakami et al. (1993). They are commonly found 
in the atmosphere, soil, and on plant leaves in close spatial proximity to stomata, where some can produce plant-growthpromoting substances (Holland, 1997; Green and Ardley, 2018). We assume that $M$. aminovorans T2 occurred in the aphid gut without having any implications for the host's adaptability to the host change. Among the other tested isolates, B. sediminis, $M$. esteraromaticum, and $B$. indicus strains were shown to tolerate nicotine at up to $8 \mathrm{~g} / \mathrm{l}$, but their growth rates were substantially reduced at this concentration. These isolates might be important facultative symbionts that facilitate the adaptation of $M$. persicae to Solanaceae-based diets. Interestingly, P. brenneri T-P1 and $P$. reactans T-P2, which were both isolated from tobacco-fed aphids, also tolerated nicotine well to a concentration of $4 \mathrm{~g} / \mathrm{l}$. This might be sufficient to facilitate the aphid's proliferation on the Solanaceae plant diets, but the detailed implications of pseudomonads under these conditions remain to be further explored.

\section{CONCLUSION}

In summary, our microbiome-guided assessment of bacterial communities in aphids subjected to different diets has shown that a transition to Solanaceae host plants resulted in substantial adaptations of their microbiome. The most evident response was the significant reduction of the primary symbiont Buchnera and the simultaneous increase of Pseudomonas. Complementary analyses revealed that facultative symbionts might facilitate the aphid's transition to secondary-metabolite-rich hosts. If the implications are confirmed, then future biotechnological developments could make use of the findings by harnessing pseudomonads that can thrive in insect guts but negatively affect the fitness and propagation of their hosts.

\section{DATA AVAILABILITY STATEMENT}

The 16S rRNA gene fragment amplicon library was deposited in European Nucleotide Archive (ENA; accession number: PRJEB42912) and the 16S rRNA gene sequences of the isolated bacteria were deposited in NCBI Genbank (accession numbers MW564208-MW564219 and MW699619-MW699622).

\section{REFERENCES}

Achal, V., Pan, X., Fu, Q., and Zhang, D. (2012). Biomineralization based remediation of As (III) contaminated soil by Sporosarcina ginsengisoli. J. Hazard. Mater. 201, 178-184. doi: 10.1016/j.jhazmat.2011.11.067

Akman Gündüz, E., and Douglas, A. E. (2009). Symbiotic bacteria enable insect to use a nutritionally inadequate diet. Proc. R. Soc. B 276, 987-991. doi: 10.1098/ rspb. 2008.1476

Alavi, S., Mitchell, J. D., Cho, J. Y., Liu, R., Macbeth, J. C., and Hsiao, A. (2020). Interpersonal gut microbiome variation drives susceptibility and resistance to cholera infection. Cell 181, 1533-1546. doi: 10.1016/j.cell.2020. 05.036

Augustinos, A. A., Santos-Garcia, D., Dionyssopoulou, E., Moreira, M., Papapanagiotou, A., Scarvelakis, M., et al. (2011). Detection and characterization of Wolbachia infections in natural populations of aphids: is the

\section{AUTHOR CONTRIBUTIONS}

TC and HY conceived the idea and developed the study design. $\mathrm{BH}$ performed all laboratory experiments under the supervision of TC, HY, and XC. TC and BH performed the bioinformatic analyses, interpreted the data, and prepared the final visualizations. HY and XC provided valuable inputs related to insect rearing and physiology. TC, HY, and BH wrote the manuscript. All authors reviewed the final version of the manuscript.

\section{FUNDING}

This work was supported by the Guizhou Provincial Science and Technology Program (grant nos. 2020-1Z021, 2019-2412, and 2019-1410) and the National Natural Science Foundation of China (grant nos. 32050410297 and 31960555$).$

\section{ACKNOWLEDGMENTS}

We would like to thank the graduate students Zhiyan Wei and $\mathrm{Li} \mathrm{He}$ (both from Guiyang, China) for their assistance with the cultivation of eggplant and pepper plants and for their help during the dissection of $M$. persicae guts. We are grateful for the tobacco seedlings provided by Yuanjing Yao, Yuanchan Yu, and Xiuxian Shen (all from Guiyang, China). In addition, we want to thank Maofa Yang and Changyu Zhang (both from Guiyang, China) that provided the infrastructure for aphid breeding and Shangwei Li (Guiyang, China) for providing the infrastructure and instruments that are part of the molecular biology laboratory (Institute of Entomology, Guizhou University).

\section{SUPPLEMENTARY MATERIAL}

The Supplementary Material for this article can be found online at: https://www.frontiersin.org/articles/10.3389/fmicb. 2021.667257/full\#supplementary-material

hidden diversity fully unraveled? PLoS One 6:e28695. doi: 10.1371/journal.pone. 0028695

Ayoubi, A., Talebi, A. A., Fathipour, Y., and Mehrabadi, M. (2020). Coinfection of the secondary symbionts, Hamiltonella defensa and Arsenophonus sp. contribute to the performance of the major aphid pest, Aphis gossypii (Hemiptera: Aphididae). Insect Sci. 27, 86-98. doi: 10.1111/1744-7917.12603

Baumann, P., Baumann, L., Lai, C. Y., Rouhbakhsh, D., Moran, N. A., and Clark, M. A. (1995). Genetics, physiology, and evolutionary relationships of the genus Buchnera: intracellular symbionts of aphids. Annu. Rev. Microbiol. 49, 55-94. doi: 10.1146/annurev.mi.49.100195.000415

Birkle, L. M., Minto, L. B., and Douglas, A. E. (2002). Relating genotype and phenotype for tryptophan synthesis in an aphid-bacterial symbiosis. Physiol. Entomol. 27, 302-306. doi: 10.1046/j.1365-3032.2002.00301.x

Blackman, R. L., and Eastop, V. F. (1984). Aphids on the World's crop. New York, NY: Wiley -Inter-science. 
Blubaugh, C. K., Carpenter-Boggs, L., Reganold, J. P., Schaeffer, R. N., and Snyder, W. E. (2018). Bacteria and competing herbivores weaken top-down and bottom-up aphid suppression. Front. Plant Sci. 9:1239. doi: 10.3389/fpls.2018. 01239

Bokulich, N. A., Kaehler, B. D., Rideout, J. R., Dillon, M., Bolyen, E., Knight, R., et al. (2018). Optimizing taxonomic classification of marker-gene amplicon sequences with QIIME 2's q2-feature-classifier plugin. Microbiome 6:90. doi: 10.1186/s40168-018-0470-z

Bolyen, E., Rideout, J. R., Dillon, M. R., Bokulich, N. A., Abnet, C. C., AlGhalith, G. A., et al. (2019). Reproducible, interactive, scalable and extensible microbiome data science using QIIME 2. Nat. Biotechnol. 37, 852-857. doi: 10.1038/s41587-019-0209-9

Brault, V., Uzest, M., Monsion, B., Jacquot, E., and Blanc, S. (2010). Aphids as transport devices for plant viruses. Comptes Rendus Biol. 333, 524-538. doi: 10.1016/j.crvi.2010.04.001

Brinza, L., Viñuelas, J., Cottret, L., Calevroa, F., Rahbé, Y., Febvaya, G., et al. (2009). Systemic analysis of the symbiotic function of Buchnera aphidicola, the primary endosymbiont of the pea aphid Acyrthosiphon pisum. Comptes Rendus Biol. 332, 1034-1049.

Callahan, B. J., McMurdie, P. J., Rosen, M. J., Han, A. W., Johnson, A. J. A., and Holmes, S. P. (2016). DADA2: high-resolution sample inference from Illumina amplicon data. Nat. Methods 13, 581-583. doi: 10.1038/nmeth.3869

Casanova, H., Ortiz, C., Peláez, C., Vallejo, A., Moreno, M. E., and Acevedo, M. (2002). Insecticide formulations based on nicotine oleate stabilized by sodium caseinate. J. Agric. Food Chem. 50, 6389-6394. doi: 10.1021/jf02 57244

De Clerck, C., Fujiwara, A., Joncour, P., Léonard, S., Félix, M. L., Francis, F., et al. (2015). A metagenomic approach from aphid's hemolymph sheds light on the potential roles of co-existing endosymbionts. Microbiome. 3, 63. doi: 10.1186/s40168-015-0130-5

Dixon, A. F. G., Kindlmann, P., Leps, J., and Holman, J. (1987). Why there are so few species of aphids, especially in the tropics. Am. Nat. 129, 580-592. doi: $10.1086 / 284659$

Dunbar, H. E., Wilson, A. C., Ferguson, N. R., and Moran, N. A. (2007). Aphid thermal tolerance is governed by a point mutation in bacterial symbionts. PLoS Biol. 5:96. doi: 10.1371/journal.pbio.0050096

Etalo, D. W., Jeon, J. S., and Raaijmakers, J. M. (2018). Modulation of plant chemistry by beneficial root microbiota. Nat. Product Rep. 35, 398-409. doi: 10.1039/C7NP00057J

Faith, D. P. (1992). Conservation evaluation and phylogenetic diversity. Biol. Cons. 61, 1-10. doi: 10.1016/0006-3207(92)91201-3

Flury, P., Aellen, N., Ruffner, B., Péchy-Tarr, M., Fataar, S., and Metla, Z. (2016). Insect pathogenicity in plant-beneficial pseudomonads: phylogenetic distribution and comparative genomics. ISME J. 10, 2527-2542. doi: 10.1038/ ismej. 2016.5

Fuchs, J. G. (2010). Interactions between beneficial and harmful microorganisms: from the composting process to compost application. Microb. Work 213:229. doi: 10.1007/978-3-642-04043-6_11

Gauthier, J. P., Outreman, Y., Mieuzet, L., and Simon, J. C. (2015). Bacterial communities associated with host-adapted populations of pea aphids revealed by deep sequencing of $16 \mathrm{~S}$ ribosomal DNA. PLoS One 10:e120664. doi: 10. 1371/journal.pone.0120664

Green, P. N., and Ardley, J. K. (2018). Review of the genus Methylobacterium and closely related organisms: a proposal that some Methylobacterium species be reclassified into a new genus, Methylorubrum gen. nov. Int. J. Syst. Evol. Microbiol. 68, 2727-2748. doi: 10.1099/ijsem.0.002856

Guo, J., Liu, X., Poncelet, N., He, K., Francis, F., and Wang, Z. (2019). Detection and geographic distribution of seven facultative endosymbionts in two Rhopalosiphum aphid species. Microbiol. Open 8:e00817. doi: 10.1002/ mbo3.817

Holland, M. A. (1997). Methylobacterium and plants. Recent Res. Dev. Plant Physiol. $1,207-212$.

Hossain, A. M., and Salehuddin, S. M. (2013). Analytical determination of nicotine in tobacco leaves by gas chromatography-mass spectrometry. Arab. J. Chem. 6:275-278. doi: 10.1016/j.arabjc.2010.10.006

Jiang, Z., Jones, D. H., Khuri, S., Tsinoremas, N. F., Wyss, T., Jander, G., et al. (2013). Comparative analysis of genome sequences from four strains of the
Buchnera aphidicola Mp endosymbion of the green peach aphid, Myzus persicae. BMC Genomics 14:917. doi: 10.1186/1471-2164-14-917

Kloepper, J. W., Ryu, C. M., and Zhang, S. (2004). Induced systemic resistance and promotion of plant growth by Bacillus spp. Phytopathology. 94, 1259-1266. doi: 10.1094/PHYTO.2004.94.11.1259

Kumar, S., Stecher, G., and Tamura, K. (2016). MEGA7: molecular evolutionary genetics analysis version 7.0 for bigger datasets. Mol. Biol. Evol. 33, 1870-1874. doi: 10.1093/molbev/msw05421

Kupferschmied, P., Maurhofer, M., and Keel, C. (2013). Promise for plant pest control: root-associated Pseudomonads with insecticidal activities. Front. Plant Sci. 4:287. doi: 10.3389/fpls.2013.00287

La Reau, A. J., Meier-Kolthoff, J. P., and Suen, G. (2016). Sequence-based analysis of the genus Ruminococcus resolves its phylogeny and reveals strong host association. Microb. Genomics 2:e000099. doi: 10.1099/mgen.0.000099

Lee, B., Lee, S., and Ryu, C. M. (2012). Foliar aphid feeding recruits rhizosphere bacteria and primes plant immunity against pathogenic and non-pathogenic bacteria in pepper. Ann. Bot. 110, 281-290. doi: 10.1093/aob/mcs055

Lee, J. B., Park, K. E., Lee, S. A., Jang, S. H., Eo, H. J., Am Jang, H., et al. (2017). Gut symbiotic bacteria stimulate insect growth and egg production by modulating hexamerin and vitellogenin gene expression. Dev. Compar. Immunol. 69, 12-22. doi: 10.1016/j.dci.2016.11.019

Lewis, Z., and Lizé, A. (2015). Insect behaviour and the microbiome. Curr. Opin. Insect Sci. 9, 86-90. doi: 10.1016/j.cois.2015.03.003

Lindeberg, M., Myers, C. R., Collmer, A., and Schneider, D. J. (2008). Roadmap to new virulence determinants in Pseudomonas syringae: insights from comparative genomics and genome organization. Mol. Plant Microbe Interact. 21, 685-700. doi: 10.1094/MPMI-21-6-0685

Lundberg, D. S., Yourstone, S., Mieczkowski, P., Jones, C. D., and Dangl, J. L. (2013). Practical innovations for high-throughput amplicon sequencing. Nat. Methods 10, 999-1002. doi: 10.1038/nmeth.2634

Ma, Y. J., He, H. P., Zhao, H. M., Xian, Y. D., Guo, H., Liu, B., et al. (2021). Microbiome diversity of cotton aphids (Aphis gossypii) is associated with host alternation. Sci. Rep. 11, 5260. doi: 10.1038/s41598-021-83675-2

Matsumoto, H., Fan, X., Wang, Y., Kusstatscher, P., Duan, J., Wu, S., et al. (2021). Bacterial seed endophyte shapes disease resistance in rice. Nat. Plants. 7, 60-72. doi: 10.1038/s41477-020-00826-5

McDonald, D., Price, M. N., Goodrich, J., Nawrocki, E. P., DeSantis, T. Z., Alexander, P., et al. (2012). An improved Greengenes taxonomy with explicit ranks for ecological and evolutionary analyses of bacteria and archaea. ISME J. 6, 610-618. doi: 10.1038/ismej.2011.139

Moran, N. A., Plague, G. R., Sandström, J. P., and Wilcox, J. L. (2003). A genomic perspective on nutrient provisioning by bacterial symbionts of insects. Proc. Natl. Acad. Sci. U.S.A. 100, 14543-14548. doi: 10.1073/pnas.2135345100

Oliver, K. M., Degnan, P. H., Burke, G. R., and Moran, N. A. (2010). Facultative symbionts in aphids and the horizontal transfer of ecologically important traits. Annu. Rev. Entomol. 55, 247-266. doi: 10.1146/annurev-ento-112408085305

Oliver, K. M., and Perlman, S. J. (2020). Toxin-mediated protection against natural enemies by insect defensive symbionts. Mechanisms Underlying Microbial Symbiosis. Adv. Insect Physiol. 58, 277-316. doi: 10.1016/bs.aiip.2020.03.005

Olmstead, R. G., and Bohs, L. (2006). A summary of molecular systematic research in Solanaceae: 1982-2006. VI Int. Solanaceae Conf. 745, 255-268. doi: 10.17660/ ActaHortic.2007.745.11

Pereira, R., Peplies, J., Mushi, D., Brettar, I., and Höfle, M. G. (2018). Pseudomonasspecific NGS assay provides insight into abundance and dynamics of Pseudomonas species including $P$. aeruginosa in a cooling tower. Front. Microbiol. 9:1958. doi: 10.3389/fmicb.2018.01958

Quaglia, F., Rossi, E., Petacchi, R., and Taylor, C. E. (1993). Observations on an infestation by green peach aphids (Homoptera: Aphididae) on greenhouse tomatoes in Italy. J. Econ. Entomol. 86, 1019-1025. doi: 10.1093/jee/86. 4.1019

Ramsey, J. S., Elzinga, D. A., Sarkar, P., Xin, Y., Ghanim, M., and Jander, G. (2014). Adaptation to nicotine feeding in Myzus persicae. J. Chem. Ecol. 40, 869-877. doi: 10.1007/s10886-014-0482-5

Robinson, M. D., McCarthy, D. J., and Smyth, G. K. (2010). edgeR: a bioconductor package for differential expression analysis of digital gene expression data. Bioinformatics 26, 139-140. doi: 10.1093/bioinformatics/btp616 
Russell, J. A., and Moran, N. A. (2006). Costs and benefits of symbiont infection in aphids: variation among symbionts and across temperatures. Proc. R. Soc. B 273, 603-610. doi: 10.1098/rspb.2005.3348

Scarborough, C. L., Ferrari, J., and Godfray, H. C. J. (2005). Aphid protected from pathogen by endosymbiont. Science 310, 1781-1781. doi: 10.1126/science. 1120180

Simonet, P., Duport, G., Gaget, K., Weiss-Gayet, M., Colella, S., Febvay, G., et al. (2016). Direct flow cytometry measurements reveal a fine-tuning of symbiotic cell dynamics according to the host developmental needs in aphid symbiosis. Sci. Rep. 6:19967.

Simonet, P., Gaget, K., Balmand, S., Lopes, M. R., Parisot, N., Buhler, K., et al. (2018). Bacteriocyte cell death in the pea aphid/Buchnera symbiotic system. Proc. Natl. Acad. Sci.U.S.A. 115, E1819-E1828. doi: 10.1073/pnas.1720237115

Stavrinides, J., McCloskey, J. K., and Ochman, H. (2009). Pea aphid as both host and vector for the phytopathogenic bacterium Pseudomonas syringae. Appl. Environ. Microbiol. 75, 2230-2235. doi: 10.1128/AEM.02860-08

Tapia, D. H., Troncoso, A. J., Vargas, R. R., Olivares-Donoso, R., and Niemeyer, H. M. (2008). Experimental evidence for competitive exclusion of Myzus persicae nicotianae by Myzus persicae s.s. (Hemiptera: Aphididae) on sweet pepper, Capsicum annuum (Solanaceae). Eur. J. Entomol. 105, 643-648. doi: 10.14411/eje.2008.088

Thompson, J. D., Higgins, D. G., and Gibson, T. J. (1994). CLUSTAL W: improving the sensitivity of progressive multiple sequence alignment through sequence weighting, position-specific gap penalties and weight matrix choice. Nucleic Acids Res. 22, 4673-4680. doi: 10.1093/nar/22.22.4673

Thompson, L. R., Sanders, J. G., McDonald, D., Amir, A., Ladau, J., Locey, K. J., et al. (2017). A communal catalogue reveals Earth's multiscale microbial diversity. Nature 551, 457-463. doi: 10.1038/nature24621

Tsuchida, T., Koga, R., Horikawa, M., Tsunoda, T., Maoka, T., Matsumoto, S., et al. (2010). Symbiotic bacterium modifies aphid body color. Science 330, 1102-1104. doi: 10.1126/science. 1195463

Urakami, T., Araki, H., Suzuki, K., and Komagata, K. (1993). Further Studies of the Genus Methylobacterium and Description of Methylobacterium aminovorans sp. nov. Int. J. Syst. Evol. Microbiol. 43, 504-513. doi: 10.1099/00207713-433-504

Van der Ent, S., Van Hulten, M., Pozo, M. J., Czechowski, T., Udvardi, M. K., Pieterse, C. M., et al. (2009). Priming of plant innate immunity by rhizobacteria and $\beta$-aminobutyric acid: differences and similarities in regulation. New Phytol. 183, 419-431. doi: 10.1111/j.1469-8137.2009.02851.x

Van Der Heijden, M. G., Bardgett, R. D., and Van Straalen, N. M. (2008). The unseen majority: soil microbes as drivers of plant diversity and productivity in terrestrial ecosystems. Ecol. Lett. 11, 296-310. doi: 10.1111/j.1461-0248.2007. 01139.x

Van der Valk, T., Vezzi, F., Ormestad, M., Dalén, L., and Guschanski, K. (2020). Index hopping on the Illumina HiseqX platform and its consequences for ancient DNA studies. Mol. Ecol. Resour. 20, 1171-1181. doi: 10.1111/1755-0998. 13009

Vieira, P. M., Marinho, L. P. M., Ferri, S., and Chen-Chen, L. (2013). Protective effects of steroidal alkaloids isolated from Solanum paniculatum L. against mitomycin cytotoxic and genotoxic actions. Anais Acad. Bras.e Ciênc. 85, 553-560. doi: 10.1590/S0001-37652013000200007

Xu, L., Xu, S., Sun, L., Zhang, Y., Lou, J., Bock, R., et al. (2021). Synergistic action of the gut microbiota in environmental RNA interference in a leaf beetle. Microbiome. 9:98. doi: 10.1186/s40168-021-01 066-1

Xu, S., Jiang, L., Qiao, G., and Chen, J. (2019). The bacterial flora associated with the polyphagous aphid Aphis gossypii Glover (Hemiptera: Aphididae) is strongly affected by host plants. Microb. Ecol. 79, 971-984. doi: 10.1007/s00248-01901435-2

Xu, S., Jiang, L., Qiao, G., and Chen, J. (2021). Diversity of bacterial symbionts associated with Myzus persicae (Sulzer)(Hemiptera: Aphididae: Aphidinae) revealed by $16 \mathrm{~S}$ rRNA Illumina sequencing. Microb. Ecol. 81, 784-794. doi: 10.1007/s00248-020-01622-6

Conflict of Interest: The authors declare that the research was conducted in the absence of any commercial or financial relationships that could be construed as a potential conflict of interest.

Copyright (c) $2021 \mathrm{He}$, Chen, Yang and Cernava. This is an open-access article distributed under the terms of the Creative Commons Attribution License (CC BY). The use, distribution or reproduction in other forums is permitted, provided the original author(s) and the copyright owner(s) are credited and that the original publication in this journal is cited, in accordance with accepted academic practice. No use, distribution or reproduction is permitted which does not comply with these terms. 